\title{
Earth's electromagnetic field by observations in Buryatia
}

\author{
Gennady Drugin ${ }^{1, \star}$, Yury Bashkuev ${ }^{2}$, Idam Naguslaeva ${ }^{2}$, Nina Cherneva ${ }^{1}$, and Boris Shevtsov ${ }^{1}$ \\ ${ }^{1}$ Institute of Cosmophysical Researches and Radio Wave Propagation FEB RAS, \\ Paratunka, Kamchatsky Kray, Russia \\ ${ }^{2}$ Institute of Physical Material Science SBRAS, \\ Ulan-Ude, Russia
}

\begin{abstract}
The data obtained by the World Wide Lightning Location Network (WWLLN) in the territory of Zabaykal'e are compared with the data received by the equipment for observations of Earth's natural pulse electromagnetic field installed in Buryatia. Diurnal and seasonal dependence of lightning strokes observed in Zabaikal'e territory were obtained. It was shown that the maxima in diurnal variation registered by the instrumentation in Buryatiya coincide with the main world lightning sources.
\end{abstract}

\section{Introduction}

Lightning activity is a hazardous phenomenon. Information on lightning may be applied in different areas of human activity. Lightning strokes can cause much damage due to the induced currents in power lines and cable links. Information on lightning is important to provide flight and navigation safety and prevention of forest fires from lightning activity. For example, it was written on [http://www.altesmedia.ru/index.php/component/k2/item/797-grozy-stali-prichinoj-pozharovv-zabajkalskom-natsionalnom-parke] that in July 2015 ?forest fires in Buryatiya were registered in the territory of Zabaykal'skiy National Park. According to the data of the Republic Forestry Agency, the cause of fires on the territories was dry lightning?

The World Wide Lightning Location Network (WWLLN) [http://wwlln.com] was developed to investigate lightning activity. It includes about 50 sites distributed all over the world. The WWLLN enables us to register lightning locations with good accuracy. However, this network records only powerful lightning strokes. In some regions of the Earth this network is not capable of registering of some lightning due to their remoteness from registration sites and a small number of sites.

In the territory of the Eastern Siberia, instrumental observations of lightning activity are carried out only in some separate regions [1,2]. Investigations of the radiation associated with the Earth natural pulse electromagnetic field (ENPEMF) are carried out in Zabaykal'e, Buryatiya. However, the registration sites in this territory are not included into the WWLLN network. Thus, at present it is impossible to monitor lightning activity and to determine the location of lightning sources there.

The aim of the paper is to define the main characteristics of radiation from lightning sources based on the data of ENPEMF registration in Buryatiya territory and to show the capabilities of WWLLN for monitoring of lightning activity in Buryatiya.

^e-mail: drug@ikir.ru 


\section{Instrumentation and methods of investigation}

Some results of the investigations and the WWLLN network are described in [3]. Registration of ENPEMF was carried out in Ulan-Ude at the Institute of Physical Material Sciences (IPMS) SB RAS. ENPEMF flux densities have been observed in VLF range by a multichannel geophysical recorder MGR-01 [4] from March 31, 2008 till the present moment [4].

According to the registration data of ENPEMF magnetic components from the north-southern and east-western directions, time dependence of pulse number for 2008-2015 was plotted (Fig. 1). Annual variation of pulse stokes has good repetition. The largest number of pulse strokes was observed in summer and reached 100000 and more, in winter time the average value of pulses did not exceed several of hundreds.
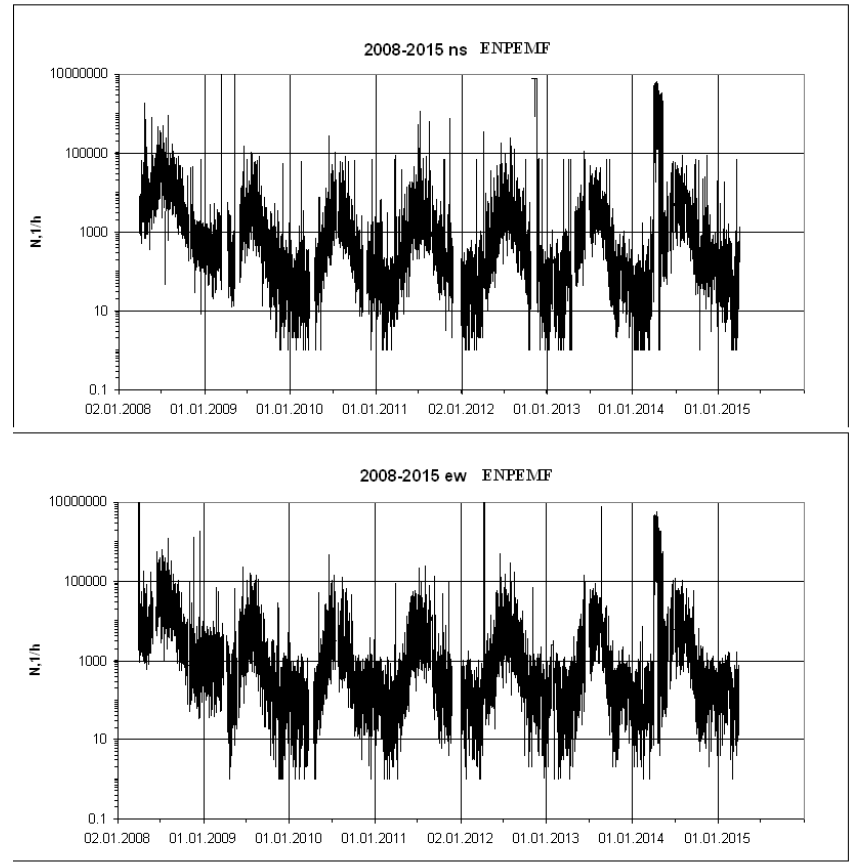

Figure 1. Lightning strokes N, recorded in Buryatiya from the north-southern (n-s) and east-western (e-w) directions for 2008-2015.

\section{Annual variation}

For detailed consideration of the annual variation, we chose the year of 2013 and plotted the dependence of pulse number recorded by WWLLN and by the instrumentation for ENPEMF from the north-southern and east-western direction (Fig. 2). The number of lighting pulses from WWLLN data was estimated from the region (Fig. 3) limited by the coordinates $\left(45^{0}-55^{0}\right) \mathrm{N},\left(100^{0}-115^{0}\right) \mathrm{E}$, in the center of which is the ENPEMF registration site, ENPEMF Ulan-Ude $\left(\varphi=51.83^{0}, \lambda=107.62^{0}\right)$. 


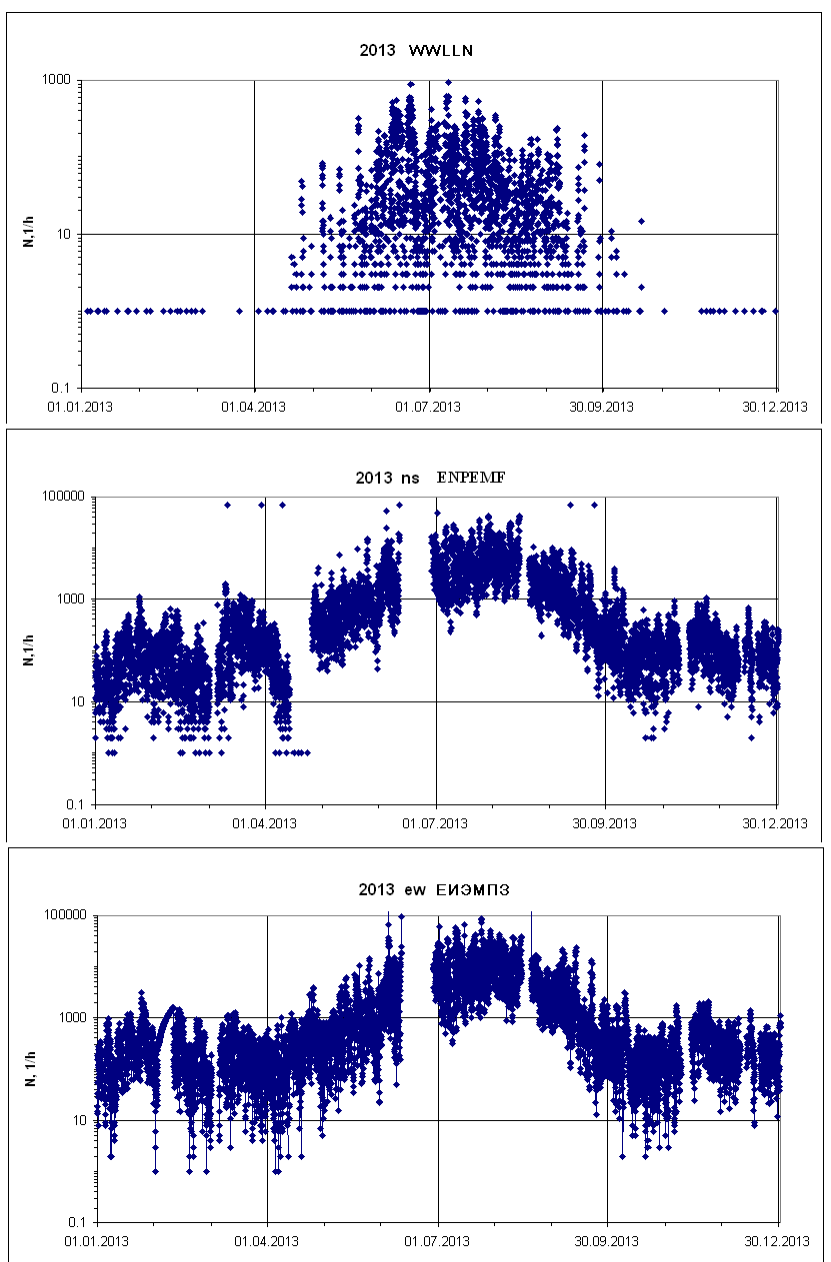

Figure 2. Lightning discharges N, recorded by the WWLLN network (at the top) and ENPEMF instrumentation from the north-southern (n-s) and east-western (e-w) directions for 2013.

It is clear from Fig. 3 that according to WWLLN, the number of lightning was $\sim(1-1000)$ 1/hour, and the pulse number recorded by ENPEMF instrumentation was ENPEMF $(1-100000)$ 1/hour. That is about two orders as much compared to the WWLLN network.

The difference in the number of recorded radiations between WWLLN and ENPEMF data may be explained by the fact that in winter time, local lightning occurs rarely and WWLLN does not detect them. However, the ENPEMF instrumentation records local and remote lightning as well as 
WWLLN Thunderstorms 22.07.2013

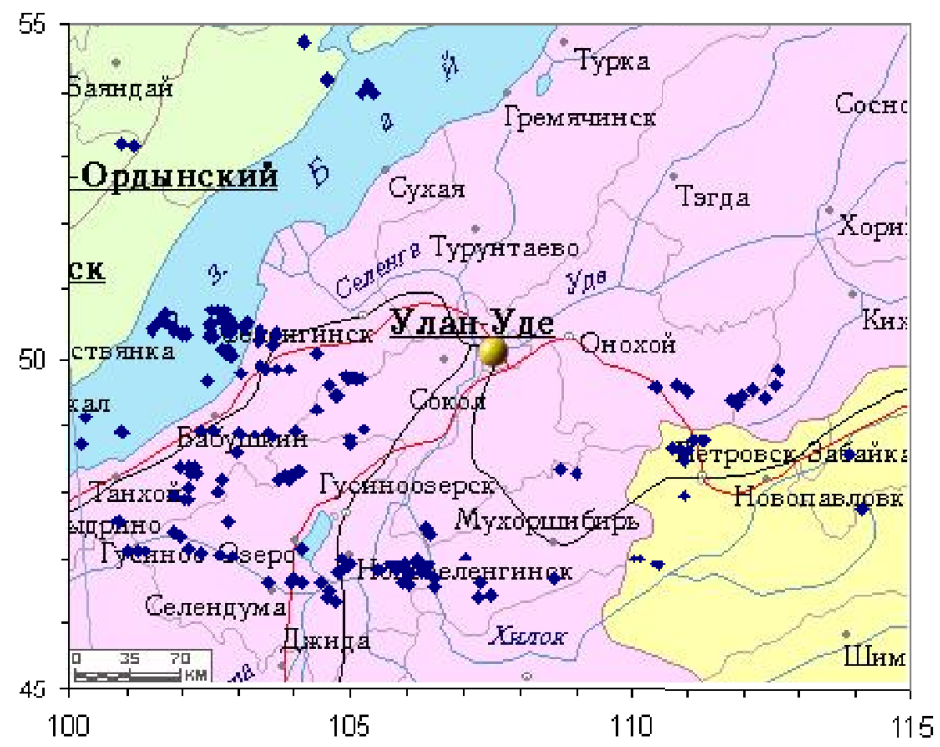

Figure 3. Zabaikal'e territory chosen to estimate the number of lightning. Squares are lightning strokes occurred on June 22, 2013.

the radiations from the world lightning sources located in the near equatorial regions of the Earth [5]. Lightning from the world sources had been registered before in the north-eastern regions of Russia which are even more distant from the equator [6].

\section{Diurnal variation}

The diurnal variations of the averaged monthly pulses recorded by the WWLLN network and by the ENPEMF site are shown in Fig. 4. The bottom part is the diurnal variation of the world lightning activity [5].

It is clear (Fig. 4,1) that in January the WWLLN recorded just a few number of lightning. In winter time, local lightning is not almost observed and there is no diurnal variation. However, quite a large number of them was recorded by the ENPEMF instrumentation with a clear diurnal variation. Its maximum value was observed at $20 \mathrm{~h} \mathrm{UTC} \mathrm{(Fig.} \mathrm{4,2-3)} \mathrm{that} \mathrm{almost} \mathrm{coincides} \mathrm{with} \mathrm{the} \mathrm{maximum}$ of lightning activity of the American lightning source (Fig. 4,14-15). Moreover, the larger number of pulses arrived from the east-western direction than from the north-southern direction. That also confirms the reception of pulses from the American lightning source which is located in the eastern 


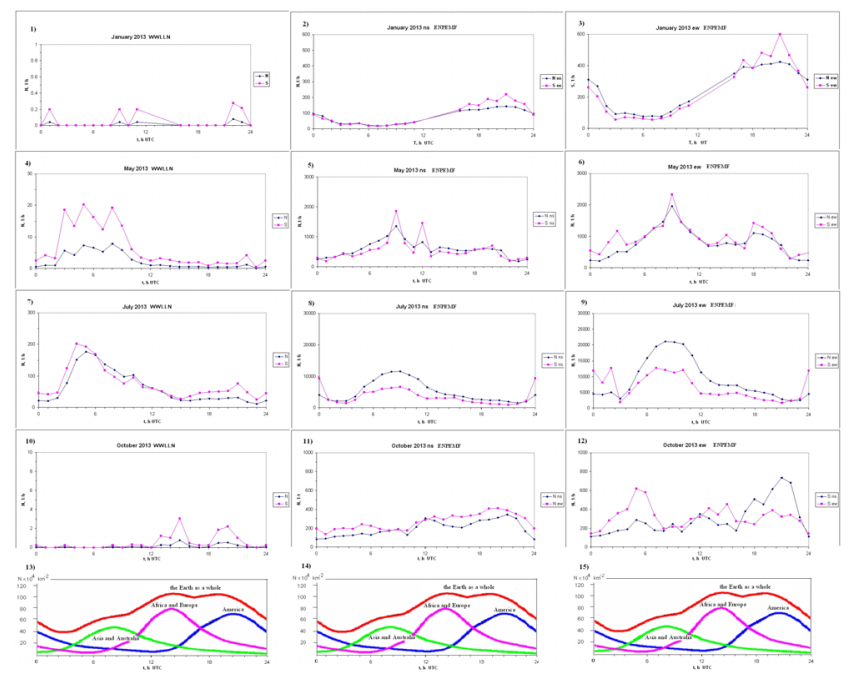

Figure 4. Diurnal variation of averaged monthly pulses received by the WWLLN network and ENPEMF station in January, May, July, November 2013 (N ? average values, S ? root mean square deviations). At the bottom are the diurnal variations of the world lightning activity.

direction from Buryatiya. Another maximum, less in values, is at $0 \mathrm{~h} \mathrm{UTC}$. It also coincides with the less maximum of lightning activity in the American lightning source.

In May the number of lightning recorded by the WWLLN network significantly increased, the diurnal variation is clearly observed with the maximum at $6 \mathrm{~h}$ UTC (Fig. 4,4). That corresponded to $16 \mathrm{~h} \mathrm{LT}$, local afternoon time in Buryatiya. From the ENPEMF data, the maximum value was at $9 \mathrm{~h}$ UTC (Fig. 4,5-6), local evening time, 19 h LT. This discordance of occurrences of the maxima may be explained by the fact that the WWLLN network records the radiation from lightning in a definite region $\left(45^{0}-55^{0}\right) \mathrm{N},\left(100^{0}-115^{0}\right) \mathrm{E}$, whereas the ENPEMF instrumentation also receives radiation out of this region, mainly from the south-eastern direction. In May, there is also the second maximum in ENPEMF at $19 \mathrm{~h} \mathrm{UTC}$, which is less in value and which almost coincides with the maximum observed in the American lightning source in January.

The annual maximum of lightning activity is observed in summer time, in July. The WWLLN network recorded the maximum number of lightning at $5 \mathrm{~h} \mathrm{UTC}$ (Fig. 4,7). The maximum of ENPEMF radiation is at $8 \mathrm{~h}$ UTC (Fig. 4,8-9). On this basis we can make a conclusion that the ENPEMF instrumentation recorded radiations outside the chosen region, supposedly from the south directions. We should also note that $8 \mathrm{~h}$ UTC almost coincides with the time of maximum activity of the Asian and Australian lightning source (Fig. 4,14-15) which is the closest one to the observation site.

In October the WWLLN network recorded a small number of lightning in the defined region (Fig. 3) and the diurnal variation was not clearly observed (Fig. 4,10) whereas the diurnal variation obtained by the ENPEMF instrumentation was clear (Fig. 4,11-12). According to the ENPEMF data, three maxima were observed. Each of them almost coincided in time with a corresponding world lightning source (Fig. 4,14-15). We may suppose that the ENPEMF instrumentation mainly recorded remote lightning in October. 


\section{Conclusions}

1. Measurements of the number of lightning strokes recorded by ENPEMF instrumentation in 20082015 in Buryatiya territory have been carried out. Diurnal and seasonal dependencies of the number of lightning strokes in Zabaikal'e territory for 2013 have been received applying the WWLLN network as well as the dependences registered by the ENPEMF instrumentation.

2. The comparative data analysis has been carried out applying the WWLLN network and the ENPEMF instrumentation recording radiations in Zabaikal'e territory. The analysis has showed that the observed number of lightning during a year changes within the range of (1 ? 1000) $1 / \mathrm{h}$, and the ENPEMF instrumentation receives pulses from lightning strokes by two orders more. The difference in number is explained by the fact that the ENPEMF instrumentation received radiations both from local and from remote sources including the world lightning centers.

3. The radiation diurnal variations from WWLLN and ENPEMF data have been compared with the diurnal variations of the African (Africa and Europe), Asian (Asia and Australia) and American lightning sources. It has been obtained that there are maxima coinciding with the world lightning centers in the diurnal variations recorded by ENPEMF instrumentation in Zabaikal'e territory.

4. Installation of WWLLN instrumentation in Buryatiya territory will allow to record lighting sources in Zabaikal'e territory with more accuracy and to respond promptly on negative processes occurring in the result of lightning activity effect.

\section{References}

[1] V.I. Kozlov, V.A. Mullayarov Thunderstorm activity in Yakutia (Pub.YB SB RAS, Yakutsk, 2004), 104

[2] G.I. Druzhin, N.V. Cherneva, A.N. Mel'nikov, Geomagnetizm and Aeronomy, 49:8, 1305-1307 (2009)

[3] R.H. Holzworth et al., Geophysical Research Letters, 31:3, 5 (2004)

[4] E.L. Afraimovichetal et al., Seismic-ionosphericand seismic-electromagnetic processes in the Baikal rift zone (House of the SB RAS, Novosibirsk, 2012), 304

[5] Handbook of geophysics (Nauka, Moscow, 1965), 571

[6] G.I. Druzhin, V.I. Shapaev, Geomagnetism and Aeronomy, 28:1, 81-86 (1988) 